\title{
Standardized Handoffs After Pediatric Residency: Retention of Practices and Perceived Importance
}

\author{
Eva Seligman ${ }^{1} \&$ Thuy $\mathrm{Ngo}^{1}$ \\ ${ }^{1}$ Division of Pediatric Emergency Medicine, Department of Pediatrics, Johns Hopkins Children's Center, \\ Baltimore, Maryland, USA \\ Correspondence: Eva Seligman, Division of Pediatric Emergency Medicine, Department of Pediatrics, Johns \\ Hopkins Children's Center, Baltimore, Maryland, USA.
}

Received: March 1, 2021

Accepted: May 6, 2021

Online Published: May 31, 2021

doi:10.20849/jed.v5i2.861

URL: https://doi.org/10.20849/jed.v5i2.861

\begin{abstract}
The I-PASS Handoff Program is linked to reduced medical errors. The enduring handoff practices of residency graduates trained in I-PASS, and attitudes thereof, are unknown. Our objective was to investigate how often residency graduates use I-PASS or other handoff tools, and perspectives regarding standardized handoffs beyond residency. We performed an exploratory electronic survey of residency graduates from programs who participated in the original I-PASS study. Responses were analyzed using descriptive statistics. Of the 106 respondents, 64/106 (60\%) identified as "attendings" and the remainder of respondents were subspeciality fellows. The most common practice setting was the inpatient hospital setting, 42/106 (39\%). Regarding handoff use, 61/106 (58\%) "rarely" or "never" used standardized handoffs. Of those using handoffs, 13/76 (17\%) used I-PASS and 59/76 (78\%) used a personal system. Most (95/101, 94\%) were unaware of any dedicated handoff training or reported it did not exist for attendings, although 77/106 (73\%) endorsed their importance for attendings. Despite rigorous residency training and belief in its importance, over one third of graduates did not use standardized handoffs. System-wide requirements for standardized handoffs may improve communication among all providers including physicians, advanced practice providers, and nurses, and enhance patient safety.
\end{abstract}

Keywords: handoff, I-PASS, communication

\section{Introduction}

Clear provider communication at shift change is a critical element to ensuring high quality patient care. Use of the I-PASS Handoff Program (I-PASS) includes a mnemonic (Illness Severity, Patient Summary, Action List, Situational Awareness, and Contingency Planning, and Synthesis by Receiver1) to standardize oral and electronic handoffs, communication training, observation, and faculty development. This program has been linked to a reduction in medical errors and preventable adverse events (Starmer et al., 2013). Although a variety of standardized handoff methods are employed throughout the country, I-PASS is used with increasing frequency. In fact, standardization of handoffs between providers has become an Accreditation Council for Graduate Medical Education (ACGME) requirement for residency programs, resulting in a generation of young physicians who are learning and practicing handoff methodology on a regular basis (ACGME, 2018). The impact of this training and the sustainability of standardized handoff use beyond residency is unknown. We sought to determine the frequency with which residency graduates continue to use I-PASS, which handoff program is otherwise used (if any), and graduates' perspectives regarding continuing standardized handoffs beyond residency. We hypothesized that the majority of respondents would not continue to use the I-PASS system despite rigorous residency training.

\section{Methods}

We electronically surveyed graduates of the original residency programs studied in the prospective, interventional I-PASS handoff study.1 Of the eleven program directors approached to participate in the study, seven consented. Two programs did not respond to the request to participate, and two programs did not have an alumni email database or list available. Program directors from three institutions elected to email the survey directly (i.e. did not provide email addresses to the investigators) and four program directors provided a list of email addresses or listserv to the investigators. The survey (available in Supplemental Material) was distributed in June 2018 to former residents graduating between 2013 and 2017; the survey tool was exploratory in nature, 
given lack of prior validated tools related to handoff practices of attending clinicians. Members of the I-PASS Study Group leadership team reviewed the survey content prior to distribution and survey questions were revised based on this feedback. Responses were fully voluntary, without participant remuneration or compensation, and with emphasis on the anonymized nature of the survey tool. A reminder email was sent one month after initial distribution to encourage participation. Responses were collected via Qualtrics software (Qualtrics LLC, Provo, UT) and anonymized so that participants' answers could not be linked with their e-mail address or institution. Results were analyzed using descriptive statistics. Dichotomous variables were reported as proportions and categorical variables were compared using Fisher's Exact test.

This study protocol was approved by the Johns Hopkins Medicine Institutional Review Board.

\section{Results}

There were 107 respondents, of which 106 affirmed that they had received I-PASS training during residency and were thus included in the final analysis. True response rate was not calculable as a large fraction of surveys were sent directly by program directors and details of these listservs were not shared with the investigators to preserve respondent anonymity. We estimated a maximum survey population of 725 individuals using publicly available residency class sizes from 2013-2017, corresponding to a minimum response rate of $15 \%$. Notably, of the 333 individuals directly contacted by the investigators, there were only $9(3 \%)$ inactive or invalid email addresses.

The survey population largely consisted of pediatrics residency program graduates $(94 / 106,88 \%)$ and the remainder trained in a combined internal medicine and pediatrics program. Over half of respondents $(59 / 106$, $56 \%$ ) completed residency greater than 24 months from the time of survey distribution and 26/106 (25\%) graduated within the past year. The majority of respondents identified their current role as an "Attending:" overall 64/106 (60\%) individuals, of which 40/106, 38\% identified as "Primary Care," $12 / 106,11 \%$ as "Hospitalist," and 12/106, 11\% as "Subspecialty". The remainder of respondents were subspeciality fellows. The study population now practices in a wide variety of primary care and subspecialty settings, and 42/106 (39\%) work in a predominately inpatient setting.

The majority of respondents $(61 / 106,58 \%$; Table 1$)$ "rarely" (1-25\% of the time) or "never" used a standardized handoff system. Of those using handoff tools, 59/106 (78\%) used a personal system and 13/106 (17\%) continued to use I-PASS (Table 1). In secondary analysis of individuals practicing primarily or entirely in an inpatient setting, there were no significant differences in responses when compared to the overall group (Table 1). Most $(95 / 105,90 \%)$ were either unaware of dedicated handoff training or reported that it did not exist for attendings at their current institution (Table 1). The majority of respondents $(77 / 106,73 \%)$ believed that standardized handoffs are important for attendings and that components should remain consistent regardless of training level $(78 / 106$, $74 \%$; Table 1).

Table 1. Spectrum of current handoff use \& attitudes toward handoffs

\begin{tabular}{lllll}
\hline Current Handoff Use & & Overall (N varies) & $\begin{array}{l}\text { Inpatient } \\
\text { varies) }\end{array}$ & (N \\
\hline Question & Response & $\mathrm{N}(\%)$ & $\mathrm{N}(\%)$ & $\mathrm{p}$-value \\
\hline Frequency of use* & Never & $40(38)$ & $9(21)$ & 0.08 \\
& $1-25 \%$ & $21(20)$ & $13(31)$ & 0.19 \\
& $26-50 \%$ & $6(6)$ & $3(7)$ & $>0.99$ \\
& $51-75 \%$ & $15(14)$ & $5(12)$ & 0.80 \\
& $76-99 \%$ & $16(15)$ & $8(19)$ & 0.62 \\
& $100 \%$ & $7(7)$ & $4(10)$ & 0.73 \\
\hline Handoff system used ${ }^{\#}$ & Individual & $59(78)$ & $27(79)$ & $>0.99$ \\
& system & $13(17)$ & $5(15)$ & 0.79 \\
& I-PASS & $4(5)$ & $2(6)$ & 1 \\
& Hospital system, & & & \\
\hline
\end{tabular}




\begin{tabular}{|c|c|c|c|c|}
\hline \multirow[t]{3}{*}{ Home institution handoff training ${ }^{\&}$} & Yes & $6(6)$ & $2(5)$ & $>0.99$ \\
\hline & No & $46(46)$ & $18(44)$ & $>0.99$ \\
\hline & Uncertain & $49(49)$ & $21(51)$ & 0.85 \\
\hline \multicolumn{2}{|l|}{ Attitudes Toward Handoffs } & Overall $(\mathrm{N}=106)$ & Inpatient $(\mathrm{N}=42)$ & \\
\hline \multirow{2}{*}{$\begin{array}{l}\text { Standardized handoffs are important } \\
\text { for ... }\end{array}$} & Agree & $95(89)$ & $33(79)$ & 0.11 \\
\hline & Disagree & $2(2)$ & $2(5)$ & 0.58 \\
\hline Residents & Neutral & $9(9)$ & $7(17)$ & 0.24 \\
\hline \multirow{3}{*}{$\begin{array}{l}\text { Standardized handoffs are important } \\
\text { for ... } \\
\text { Fellows }\end{array}$} & Agree & $84(79)$ & $26(62)$ & 0.04 \\
\hline & Disagree & $6(6)$ & $5(12)$ & 0.29 \\
\hline & Neutral & $16(15)$ & $11(26)$ & 0.16 \\
\hline \multirow{3}{*}{$\begin{array}{l}\text { Standardized handoffs are important } \\
\text { for ... } \\
\text { Attendings }\end{array}$} & Agree & $77(73)$ & $24(57 \%)$ & 0.08 \\
\hline & Disagree & $5(5)$ & $4(10)$ & 0.45 \\
\hline & Neutral & $24(23)$ & $14(33)$ & 0.21 \\
\hline \multirow{3}{*}{$\begin{array}{l}\text { The general elements of a handoff } \\
\text { system should be the same, } \\
\text { regardless of training level. }\end{array}$} & Agree & $78(73)$ & $26(62)$ & 0.17 \\
\hline & Disagree & $19(18)$ & $11(26)$ & 0.36 \\
\hline & Neutral & $9(9)$ & $5(12)$ & 0.54 \\
\hline
\end{tabular}

Notes: *105 responses in "Overall group" and 42 responses in "Inpatient" group.

\#76 responses in "Overall" group and 34 responses in "Inpatient" group.

$\& 101$ responses in "Overall group and 41 responses in "Inpatient" group.

\section{Discussion}

Breakdowns in provider communication result in a large proportion of medical errors each year, (CRICO Strategies, 2015) and provider handoffs are particularly vulnerable to communication lapses (The Joint Commission, 2017). The profound reduction of medical errors (Mueller, Yoon, \& Schnipper, 2016; Starmer et al., 2013) and improvement in resident self-efficacy (Coffey et al., 2017; Seligman \& Malakooti, 2018) after implementation of standardized handoff tools demonstrated in previous studies suggest the potential for standardized handoffs to improve patient care and communication beyond residency. A recent study of handoff implementation in a private hospital with attending physicians echoed prior studies demonstrating reduction in errors without an increase in work load or duration of handoff (Roig et al., 2020). Some institutions have also attempted hospital-wide adaptation of standardized handoffs resulting in a decreased report of nursing handoff errors and physician report of improved personal and general handoffs (Blazin, Sitthi-Amorn, Hoffman, \& Burlison, 2020). Despite rigorous residency training in standardized handoffs, belief in its importance for all levels of providers, and a growing body of literature to support its efficacy, we found that over one-third of graduates use no such system. To our knowledge, there are no national requirements that govern handoff practices beyond residency. A lack of national requirements may be problematic, as nearly $70 \%$ of physicians will change jobs within the first two years of practice ("Leaving so soon? | Today's Hospitalist," n.d.). This flux implies that exposure to multiple different care environments is quickly becoming the norm. The use and consistent practice of standardized handoffs may mitigate the variability of communication in clinical environments as individuals migrate between institutions.

Most providers in our study were also not aware of dedicated handoff training for non-resident providers at their current institution. In many institutions, on-going handoff practices may be variable and unmonitored (Blondon, Wipfli, Nendaz, \& Lovis, 2015). Effective communication may be even more challenging without a culture of standardized handoffs established by hospital leadership and later career clinicians. Without dedicated training in communication strategies, such individuals may not realize the intricacies of an effective handoff. Ideally, essential information is included in a timely manner and the electronic medical record or written element of the handoff appropriately supplements, but does not replace, face-to-face communication. ("Better handoffs | ACP Hospitalist," n.d.) Studies of resident physicians have demonstrated that handoffs do not negatively impact efficiency or workload (Starmer et al., 2013). In these studies, however, dedicated training and then monitoring of handoffs were essential to success. In the last decade there has been a large uptick in peer-reviewed literature 
addresing the feasibility and efficacy of standardized handoffs in a variety of settings ("PubMed," 2021). This trend may demonstrate a changing mentality toward wider implementation and a commitment to training and on-going monitoring of handoff practices of all healthcare providers.

Interpretation of the results of this study is limited by the inability to enumerate the true number of individuals who were solicited to participate in this study overall and low estimated response rate. Anonymity was a condition for some of the program directors' agreement to participate, limiting tracking of responses by institution as well as overall proportion of inactive or inaccurate email addresses. There may be inherent bias in the individuals who chose to respond to this voluntary survey, perhaps skewed toward extreme perceptions of handoffs and a mentality invested in participating in research and handoffs in general. Additionally, our study did not include the perspectives of more practiced clinicians (training prior to I-PASS), and their knowledge of standardized handoff communication remains unknown. Despite these limitations, we believe that the information from the responses collected provides valuable insight into attending handoff practices and are important for hypothesis generating for future studies and professional development projects.

\section{Conclusion}

This study is the first to our knowledge to assess physicians' personal use of standardized handoff tools and general attitudes toward handoffs after rigorous training during residency. Low rates of utilization of standardized handoff in our study population may indicate an area to emphasize for professional development and continuing medical education. Overall, implementation of training programs and system-wide requirements for standardized handoffs may enhance patient safety and communication among all medical providers, including advanced practice providers and nursing staff. Successful development of these educational programs will require institution-wide commitment to provider training, ensuring sustainability and monitoring of the handoff process.

\section{Acknowledgments}

The authors wish to thank the members of the I-PASS Study Group leadership, particularly Nancy D. Spector, $\mathrm{MD}$, for support of and insight into this project. We would also like to thank the program leadership and graduates of the included pediatric and/or combined medicine-pediatrics residencies for their participation in this project.

\section{References (排序)}

ACGME. (2018). ACGME Common Program Requirements (Residency). Retrieved from https://www.acgme.org/Portals/0/PFAssets/ProgramRequirements/CPRResidency2019.pdf

Better handoffs, ACP Hospitalist. (n.d.). Retrieved January 7, 2020, from https://acphospitalist.org/archives/2016/12/improving-handoffs.htm

Blazin, L. J., Sitthi-Amorn, J., Hoffman, J. M., \& Burlison, J. D. (2020). Improving patient handoffs and transitions through adaptation and implementation of I-PASS across multiple handoff settings. Pediatric Quality \& Safety, 5(4), e323. https://doi.org/10.1097/pq9.0000000000000323

Blondon, K. S., Wipfli, R., Nendaz, M. R., \& Lovis, C. (2015). Physician handoffs: opportunities and limitations for supportive technologies. AMIA Annual Symposium Proceedings. AMIA Symposium, 2015, 339-348.

Coffey, M., Thomson, K., Li, S.-A., Bismilla, Z., Starmer, A. J., O’Toole, J. K., ... Landrigan, C. P. (2017). Resident experiences with implementation of the I-PASS handoff bundle. Journal of Graduate Medical Education, 9(3), 313-320. https://doi.org/10.4300/JGME-D-16-00616.1

CRICO Strategies. (2015). Malpractice risk in communication failures; 2015 Annual Benchmarking Report. The Risk Management Foundation of the Harvard Medical Institutions.

Leaving so soon? Today's Hospitalist. (n.d.). Retrieved February 19, 2020, from https://www.todayshospitalist.com/leaving-so-soon/

Mueller, S. K., Yoon, C., \& Schnipper, J. L. (2016, September). Association of a web-based handoff tool with rates of medical errors. JAMA Internal Medicine. American Medical Association. https://doi.org/10.1001/jamainternmed.2016.4258

$\begin{array}{lllll}\text { PubMed. } & \text { (n.d.). } & \text { Retrieved } & \text { May } & \text { f021, }\end{array}$ https://pubmed.ncbi.nlm.nih.gov/?term=physician+handoff\&filter=datesearch.y_1

Roig, C. G., Viard, M. V., Elorrio, E. G., Anzorena, I. S., Barón, F. J., Veloso, C. C., ... Gibson, C. G. (2020). Implementation of a structured patient handoff between health care providers at a private facility in the 
Autonomous City of Buenos Aires. Archivos Argentinos de Pediatria, 118(3), E234-E240. https://doi.org/10.5546/aap.2020.eng.e234

Scott, A. M., Li, J., Oyewole-Eletu, S., Nguyen, H. Q., Gass, B., Hirschman, K. B., ... Project Achieve Team. (2017). Understanding facilitators and barriers to care transitions: insights from project achieve site visits. Joint Commission Journal on Quality and Patient Safety, 43(9), 433-447. https://doi.org/10.1016/j.jcjq.2017.02.012

Seligman, E., \& Malakooti, M. (2018). Implementation of LURIES: A New Handoff Tool for Pediatric Residents. Cureus. https://doi.org/10.7759/cureus.2558

Starmer, A. J., Sectish, T. C., Simon, D. W., Keohane, C., McSweeney, M. E., Chung, E. Y., ... Landrigan, C. P. (2013). Rates of medical errors and preventable adverse events among hospitalized children following implementation of a resident handoff bundle. JAMA, 310(21), 2262. https://doi.org/10.1001/jama.2013.281961

The Joint Commission. (2017). Sentinel Event Alert: Inadequate hand-off communication. Retrieved from www.jointcommission.org

\section{Appendix A}

\section{Supplemental Material - Survey Content}

Handoff Habits after Residency

Q1: You are being asked to complete this survey because you attended residency at an I-PASS site. We are now interested in learning about your current handoff practices.

Completion of this anonymous survey is voluntary and you may choose to stop at any time. If you have questions or comments, then please contact Eva Seligman (eseligm2@jhmi.edu).

This study has been approved by the Johns Hopkins University IRB.

Your completion of the survey will serve as your consent to be in this research study.

Q2: How would you describe your I-PASS training during residency?

I received annual training in I-PASS

I received training in I-PASS at some point during residency

I did not receive I-PASS training

Q3: How would you describe your use of I-PASS during residency?

I used I-PASS throughout residency

I-PASS was introduced during my residency, so I used it for part of the time

I never used I-PASS

Q4: Currently, how often do you use a standardized system when handing off patients?

Never

$1-25 \%$ of the time

$26-50 \%$ of the time

$51-75 \%$ of the time

$79-99 \%$ of the time

$100 \%$ of the time 
Q5: If you do use a standardized handoff system currently, which system do you use?

A personal system

Hospital/clinic-wide system that is I-PASS

Hospital-wide system that is not I-PASS (name system used)

Q6: If you work with trainees (medical students, residents), do they use a standardized handoff system?

Yes (1)

No (2)

Uncertain (3)

I do not work with trainees

Q7: If residents use a standardized handoff system, do the providers at your level of training use the same system?

Yes (1)

No (2)

Uncertain (3)

Q8: Does your institution have dedicated handoff training for attendings?

Yes (1)

No (2)

Uncertain (3)

Q9: It is important for residents to use a standardized handoff system.

Agree (1)

Disagree (2)

Neutral (3)

Q10: It is important for fellows to use a standardized handoff system.

Agree (1)

Disagree (2)

Neutral (3)

Q11: It is important for attendings to use a standardized handoff system.

Agree (1)

Disagree (2)

Neutral (3)

Q12: The general elements of a handoff system should be the same, regardless of training level.

Agree (1)

Disagree (2)

Neutral (3) 
Q13: With which gender do you identify?

Male (1)

Female (2)

Other (3)

I prefer not to answer (4)

Q14: How long ago did you graduate from residency?

0-12 months ago (1)

$12-24$ months ago

2 years ago (please list year)

(3)

Q15: How many residents were in your class?

$<15 \quad(1)$

$15-30 \quad(2)$

$>30 \quad(3)$

Q16: How would you describe your current practice setting?

Primary care, outpatient only

Primary care outpatient mostly with occasional inpatient coverage

Subspecialty care, outpatient only

Subspecialty outpatient care with occasional inpatient coverage

Mostly general inpatient coverage with occasional outpatient clinic

Mostly subspecialty inpatient coverage with occasional outpatient clinic

Inpatient general medicine/pediatrics only

Inpatient subspecialty care only

Emergency department

Q17: If you identified that you work in an inpatient or emergency department setting, how would you characterize the hospital?

Private community based, not a teaching institution

Not-for-profit community based, not a teaching institution

Community-based teaching institution

(3)

Academic center

Other (please specify)

I do not work in an inpatient or emergency room setting

Q18: How would you best describe your current role?

Subspecialty fellow

Subspecialty attending

Hospitalist

Primary care attending

Other (please specify)

(5) 
Q19: From which type of residency did you graduate?

Pediatrics

Internal Medicine

Family Medicine

Combined Medicine-Pediatrics

Other (please specify)

(5)

Q20: Unique identifier (this will be used to track for multiple submissions by the same individual and will not be traced to specific respondents). Please enter your street number, the first letter of your last name, and the number of pets that you have. Example: John Smith lives at 1455 North Pole Ave and has 8 reindeer, his code is 1455 S 8

\section{Copyrights}

Copyright for this article is retained by the author(s), with first publication rights granted to the journal.

This is an open-access article distributed under the terms and conditions of the Creative Commons Attribution license (http://creativecommons.org/licenses/by/4.0/). 